\title{
Proceeding
}

11th World Congress of Performance Analysis of Sport, 16-18 November 2016. International Society of Performance Analysis of Sport. Alicante, Spain

\section{The use of timeouts in volleyball, depending on the team score}

\author{
ANTONIO ABREU ${ }^{1}$, CARMEN FERNÁNDEZ-ECHEVERRIA ${ }^{1} \triangle$, JARA GONZALEZ-SILVA ${ }^{1}$, FERNANDO \\ CLAVER $^{2}$, MANUEL CONEJERO ${ }^{1}$, M. PERLA MORENO ${ }^{1}$ \\ ${ }^{1}$ Faculty of Sport Sciences, University of Extremadura, Spain \\ ${ }^{1}$ Faculty of Health Sciences, Miguel de Cervantes European University, Spain
}

\begin{abstract}
In the management of team sport competition, timeouts are one of the main tools of the coach to stop the game. It could be used on changing trends or the rhythm of the game, and also on providing relevant information to the players. So, it may have an important effect in sporting success. The main objective of the research was to analyse the use of timeouts (TO) in U-19 male volleyball teams, as well as the effect of the game on then, depending on the match score (winning-balanced, or losing). 171 timeouts, requested by coaches of the 21 teams participating in the U-19 male Spanish Championship 2012, were analysed. The variables considered in this study were: match score (TO requested when winning-balanced score or when losing); score difference (0-1 points, 2-3 points, 4 or more points); lost rallies ( $0-1$ rallies, 2 rallies, $\geq 3$ rallies); game period (initial moment of the set, final moment of the set); timeout effect (positive timeout effect and time out with no effect). The results showed that variables significantly associated with the TO request with different score (winning-balanced, losing) were: score difference, game period and timeout effect. Specifically, contributed positively to the association: TO request with winning-balanced score with the score difference of 0-1 points, with the final moments of the set and with the positive timeout effect; TO request with a losing score with the score difference of 4 or more points, in the initial moments of the set and with no effect of the timeout. This results could be taken into account in the process of team management in competition, in volleyball formative stages. Key words: TIMEOUTS, VOLLEYBALL, MATCH SCORE, FORMATIVE STAGES.
\end{abstract}

\section{Cite this article as:}

Abreu, A., Fernández-Echeverría, C., González-Silva, J., Claver, F., Conejero, M., \& Moreno, M.P. (2017). The use of timeouts in volleyball, depending on the team score. Journal of Human Sport and Exercise, 12(3proc), S813-S820. doi:https://doi.org/10.14198/jhse.2017.12.Proc3.05

\footnotetext{
Corresponding author. Facultad de Ciencias del Deporte, Universidad de Extremadura, Av. Universidad, s/n, 10003 Cáceres, Spain.

E-mail: cafernandeze.unex.es

11th World Congress of Performance Analysis of Sport, 16-18 November 2016. International Society of Performance Analysis of Sport. Alicante, Spain.

JOURNAL OF HUMAN SPORT \& EXERCISE ISSN 1988-5202

(c) Faculty of Education. University of Alicante

doi:10.14198/jhse.2017.12.Proc3.05
} 


\section{INTRODUCTION}

During the team management in competition, in different collective sports, the coaches have the possibility to request time-outs or rest times. These can be managed freely by the coach and depending on the sports, can be requested by a determined number of timeouts, with a duration established by the sports regulation (Gómez et al., 2011; Mace et al., 1992; 2004, Wang et al., 2010).

Specifically, in volleyball, the regulation allows the coach of each team to request two timeouts per set, with a duration of 30 seconds. To request it, the coach must press the manual signal, when the ball is not in play (FIVB, 2015, article 15.4).

The objective of these interruptions in the game is to influence the rhythm of the game, through a pause during the game and also through specific indications by the coach that could affect the sports performance of subsequent actions (Moreno et al., 2005). Therefore, time-outs are one of the main tools that coaches have to intervene and directly influence in the most relevant actions in the game (Ortega et al., 2007, Rodrigues 2000, Sampaio et al., 2006, Zetou Et al., 2008).

Due to the importance of an optimal management of this tool by the coaches, there are several studies that had tried to know its use (Garcia-Tormo et al., 2003), the reasons that coaches have to request the timeout (Herrera et al., 1996, Zetou et al., 2008, Zhang, 1993), and the effect they have on the game (Gomes et al., 2014, Permutt, 2011, Valle et al., 2012).

Specifically in volleyball, studies that have focused on knowing the reasons for requesting timeout indicate that time-out is requested primarily when teams are down in the score (Zetou et al., 2008) and when the opposing team win between one and the points consecutively (García-Tormo et al., 2003, FernándezEcheverría et al., 2013). In addition, another issue that is focused on research is the timeout effect in the game. In this sense, Garcia-Tormo et al. (2003) showed that the request of the timeout allows the requesting team, in $77.77 \%$ of the occasions, to break the streak of the rival team in the play immediately after the request, or into the next play.

Despite the literature highlight a mayor frequency of TO requests when the team is down in the score (Zetou et al., 2008), there are times in what coaches make use of this tool into a balance or winning score. Therefore, the main objective of the research was to analyse the use of timeouts in the U-19 male volleyball teams, as well as their effect, depending on the match score (winning-balanced or lose).

\section{MATERIAL AND METHODS}

\section{Participants}

The study sample was comprised of 171 timeouts, requested by coaches of the 21 teams participating in the U-19 male Spanish Championship 2012. The timeouts analysed correspond to the observation of a match played by each team.

The protocol was fully approved by the Research Ethics Committee of the University of Extremadura (Spain). The team coaches were contacted in advance, informing them of the confidentiality of the data and guaranteeing their anonymity. All players and their parents or guardians were fully informed about the study, and they signed a consent form. 


\section{Measures}

The variables considered in the study were the following: match score, score difference, lost rallies, game period and timeout effect. The degree of openness of each one of the variables is indicated below.

- Match score: defined as the situation of the team with respect to the score when the timeout is requested. The following values were differentiated:

- Winning-balanced score.

- Losing.

- Score difference: defined as the difference in score between the teams when the timeout is requested. The following values were differentiated:

$-0-1$ points.

- 2-3 points.

- 4 or more points.

- Lost rallies: defined as the number of consecutive moves that occur whilst the opposite team is in possession of the serve, until the timeout is requested. The following values were differentiated:

$-\leq 2$ rallies.

-3 rallies.

$-\geq 4$ rallies.

- Game period: defined as the moment of the set in what the timeout was ordered. The following values were differentiated:

- Initial moment of the set 1, 2, 3 and 4 (1-16 points). Initial moment of the set 5 (1-8 points).

- Final moment of the set 1, 2, 3 and 4(17-25 points.) Final moment of the set 5 (9-15 points).

- Timeout effect: defined as the consequence on the game (in relation to recover or not the service) of requesting a timeout. The following values were differentiated:

- Positive timeout effect: defined as the team that has requested the timeout recovers the serve in the first rally in $\mathrm{K} 1$.

- Timeout with no effect: defined as the team that has requested the timeout no recovers the serve in the first rally in $\mathrm{K} 1$.

\section{Procedures}

To guarantee the validity of the instruments, a group of four researchers, experts in volleyball (Graduates in Physical Activity and Sport Sciences, National Level III Volleyball Coaches, with experience as volleyball coaches), developed the observation instrument in agreement with the theoretical framework and based on existing bibliography.

For the reliability of the observation, after collecting the video footage and previously to the coding process, one observer (Graduate in Physical Activity and Sport Sciences, National Level III Volleyball Coach) was trained to observe the study variables. In this training process, he observed different situations (winningbalanced score and losing) that exceeded the $10 \%$ of the total simple, indicated by Tabachnick and Fidell (2013). The intra-observer Cohen's Kappa values reached, in the observation of all the variables, were higher than .81 , in the third training session, which was the minimum value considered to be almost perfect 
agreement. To guarantee the time reliability of the measurement, the same coding was developed on two occasions, with a time difference of 10 days, obtaining Cohen's Kappa values of over .81 .

\section{Data collection}

The matches were recorded using a SONY HDR-XR155 digital camera on M2TS format. This camera was located at one of the ends of the court, guaranteeing a height of $5 \mathrm{~m}$ above floor level and a distance of 7 metres behind the baseline, to obtain an optimal line of sight.

\section{Statistical analysis}

The data analysis is composed of an inferential analysis, carried out based on the contingency tables, the Chi Square values and Cramer's V, to analyse the possible existing associations between the different variables considered in the study. The conditions of validity were guaranteed to be able to apply the Chi Square Test (minimum frequency expected is greater than one and no more than $20 \%$ of the boxes of the table have expected frequencies of less than five). To analyse the corrected residuals, a value of $>2$ was taken to establish an excitatory relationship and $<-2$ to establish an inhibitory relationship. The statistical significance level considered was $p<.05$.

Statistical analysis of data was performed using SPSS 19.0.

\section{RESULTS}

Then, we present an inferential analysis of the variable match score with the other variables considered in the study:

- Match score- Score difference

The inferential analysis told us that there was a significant association between match score and score difference $\left(X^{2}=12.456\right.$; Cramer's $\left.V=.270 ; p<.05\right)$. The cells that positively contributed to this association were: the score difference of 0-1 points with winning-balanced score, and the score difference of 4 or more points with losing.

Table 1. Inferential analysis Match score - Score difference.

\begin{tabular}{lllccc}
\hline & & \multicolumn{3}{c}{ Match score } & \\
\cline { 3 - 5 } Score difference & 0-1 Points & Count & 11 & 11 & 22 \\
& & Expected frequency & 16.9 & 5.1 & 22.0 \\
& & Adjusted residuals & -3.2 & 3.2 & \\
\cline { 3 - 5 } & 2-3 Points & Count & 38 & 14 & 52 \\
& & Expected frequency & 39.8 & 12.2 & 52.0 \\
& & Adjusted residuals & -.7 & .7 & \\
\cline { 3 - 5 } & \multirow{2}{*}{4 or more points } & Count & 82 & 15 & 97 \\
& & Expected frequency & 74.3 & 22.7 & 97.0 \\
& & Adjusted residuals & 2.8 & -2.8 & \\
\hline Total & Count & 131 & 40 & 171 \\
\hline
\end{tabular}

0 boxes (.0\%) have an expected frequency of less than 5 . The minimum expected frequency is 5.15 . 
- Match score- Lost rallies

The inferential analysis indicated that there is not a significant association between both variables $\left(X^{2}=3.618\right.$; Cramer's V =.145; $p=.164$ ).

\section{- Match score- Game period}

The inferential analysis told us that there was a significant association between match score and game period $\left(X^{2}=7.640\right.$; Cramer's $\left.V=.211 ; p<0.05\right)$. The cells that positively contributed to this association were: the final moments of the set with winning-balanced score, and the initial moment of the set with losing.

Table 2. Inferential analysis Match score - Game period.

\begin{tabular}{cllccc}
\hline & & \multicolumn{3}{c}{ Match score } & \\
\cline { 3 - 5 } Game period & Initial moment & Count & Losing & Winning-balanced score & Total \\
\cline { 3 - 5 } & $(1-16$ points $)$ & Expected frequency & 64.4 & 12 & 84 \\
& & Adjusted residuals & 2.8 & 19.6 & 84.0 \\
\cline { 2 - 5 } & Final moments & Count & 59 & 2.8 & 87 \\
& $(17-25$ points $)$ & Expected frequency & 66.6 & 20.4 & 87.0 \\
& & Adjusted residuals & -2.8 & 2.8 & \\
\hline Total & & Count & 131 & 40 & 171 \\
\hline
\end{tabular}

0 boxes (.0\%) have an expected frequency of less than 5 . The minimum expected frequency is 19.65 .

- Match score - Timeout effect

The inferential analysis told us that there was a significant association between match score and timeout effect $\left(X^{2}=26.834\right.$; Cramer's $\left.V=.396 ; p<.01\right)$. The cells that positively contributed to this association were: the positive timeout effect with winning-balanced score, and the timeouts with no effect with losing.

Table 3. Inferential analysis Match score - Timeout effect.

\begin{tabular}{lllccc}
\hline & & \multicolumn{3}{c}{ Match score } & \\
\cline { 3 - 5 } & & & Losing & Winning-balanced score & Total \\
\hline Timeout effect & Positive timeout & Count & 41 & 31 & 72 \\
& & Expected frequency & 55.2 & 16.8 & 72.0 \\
& Timeouts with no effect & Adjusted residuals & -5.2 & 5.2 & \\
\cline { 3 - 5 } & Count & 90 & 9 & 99 \\
& & Expected frequency & 75.8 & 23.2 & 99.0 \\
& Adjusted residuals & 5.2 & -5.2 & \\
& Count & 131 & 40 & 171 \\
\hline Total & & & & &
\end{tabular}

0 boxes (.0\%) have an expected frequency of less than 5 . The minimum expected frequency is 16.84 . 


\section{DISCUSSION AND CONCLUSIONS}

The main objective of the research was to analyse the use of timeouts (TO) in U-19 male volleyball teams, as well as their effect on the match score (winning-balanced, or losing).

Our results showed a significant association between match score and score difference, in such a way that requesting the timeout with the balanced-winning score is positively associated with a score difference of 0 1 points, and requesting the timeout when losing associates positively with a score difference of 4 or more points.

Several investigations carried out in different sports have taken into account the variable score difference considered in our study (Gomes et al., 2011; Gómez et al., 2014). Specifically, in line with our results, the study by Zetou et al. (2008) shows that coaches request timeouts more frequently when the points difference is two $(22 \%)$, three $(18.7 \%)$ and four (18\%). However, this study does not detail whether the request is made with a result for or against.

Our results expose the relevance of requesting a time-out with small differences in the score, to prevent the opposing team from advancing on it (Mace et al., 1992). However, when the team is down in the scoreboard, the coaches expect to request such timeouts with greater differences in the scoreboard, delaying a little more the request. In both cases, the score difference is a variable to be taken into account in the request of timeouts (Mace et al., 1992; Zetou et al., 2008).

Our results show a not significant association between match score and lost rallies. In line with our work, previous studies in volleyball have analysed the number of lost rallies that usually take place before the coaches request a time-out. In particular, these studies indicate that the highest percentage of timeouts are requested after 1 or 2 lost rallies (Fernández-Echeverría et al., 2013, Gil et al., 2010).

Our results show that coaches request timeouts with a similar number of lost rallies when a balanced-winning or losing score. These results are in line with the existing literature, which indicates that one of the reasons that leads the coach to request a timeout is not to score during a certain time interval, while the opposing team continues scoring (Gomes et al., 2014).

Our results show a significant association between match score and game period, in such a way that requesting the timeout with the balanced or winning score is positively associated with the final moments of the set, and requesting the time-out when losing is positively associated with the initial moment of the set.

In addition to the results obtained, previous studies in different sports have analysed the moments of the game in which timeout is requested (García-Tormo et al., 2006, Sampaio et al., 2013 and Zetou et al., 2008). Specifically, volleyball research show the tendency of coaches to space the timeout request throughout the set, not leaving the two possible requests to the final stage. Usually the first of them is used when the result is not definitively unbalanced and there are still possibilities that the coach can intervene in the game of his team (García-Tormo et al., 2006; Zetou et al., 2008). However, such works do not take into account match score at the time of the timeout request. Therefore, our study provides new information on the moment of requesting the time-outs. We state that the coaches of these stages use, more than expected by random, timeouts at the beginning of set if the team goes down in the result. On the other hand, if this is not the case, coaches of these stages use, more than expected by random, the timeout at the final moments of the set, where they may need to request a timeout in key moments where the opponent can approach on the score. 
Our results show a significant association between match score and timeout effect, in such a way that requesting a timeout with the balanced or winning score is positively associated with the positive timeout effect, and requesting the timeout when losing is positively associated with the timeouts with no effect.

In line with our work, previous studies in volleyball have been concerned with knowing the effect of timeout. Specifically, García-Tormo et al. (2003) analysed 144 timeouts requested by the coaches of the teams participating in the U-19 Spanish Championship, in the season 2002/2003. This work indicates that in $77.77 \%$ of the occasions the timeouts allow the requesting team to break the opponent's streak in the game immediately after the same or in the next play. These results are in line with those obtained by Gil et al. (2010).

In our study, we also wanted to know if that positive effect of the time-out was similar requested in a winningbalanced or losing score. Our results show the utility of requesting these timeouts not only when losing but also in those moments that, despite having the winning score, the opposing team approaches or balance the score. In addition, although our results seem to indicate that timeouts are not effective with the result against, these results must be considered with caution, since we considered the effect of the time-out depending of the result of the next action, although the timeout effect could be manifested after that. Added to the above, when the teams go down in the scoreboard (if the level of the teams is unbalanced), winning the following action to the request can be difficult, despite its usefulness to give indications and corrections.

Finally, we can indicate that timeout is not only a useful tool when the team is at a disadvantage in the scoreboard, but can also have positive consequences when the team is winning or balanced, and its performance has decreased.

\section{ACKNOWLEDGEMENTS}

This work was supported by the Consejería de Economía e Infraestructuras de la Junta de Extremadura (Spain) through the European Regional Development fund.

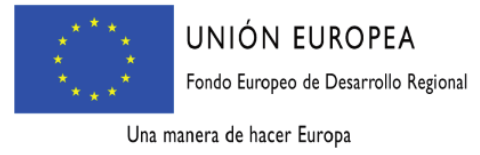

\section{JUNTA DE EXTREMADURA}

Consejería de Economía e Infraestructuras

\section{REFERENCES}

1. Fernández-Echeverría, C., Gil, A., García-González, L., Carrasco, F., Claver, F., \& Del Villar, F. (2013). Employment time out in volleyball formative stages. J. Hum. Sport Exerc, 8(3), 591-600. https://doi.org/10.4100/jhse.2013.8.Proc3.04

2. FIVB (2015). Official volleyball rules 2015. Lausanne: Fédération Internationale de Volleyball.

3. García-Tormo, J. V., Valladares, J. A., \& Morante, J. C. (2003). Análisis de la eficacia de los tiempos muertos solicitados durante el Campeonato de España Juvenil Femenino 2003. Comunicación presentada en el III Congreso Internacional de entrenadores en Voleibol, Valladolid.

4. Gil, A., Moreno, M. P., Moreno, A., García-González, L., \& Del Villar, F. (2010). Análisis de los tiempos muertos en competición de voleibol en categorías de formación. Comunicación presentada en el II Congreso Internacional de Ciencias del Deporte y Educación Física. Pontevedra. 
5. Gomes, F., Volossovitch, A., \& Ferreira, A. P. (2014). Team timeout calling in handball. Int J Perform Anal Sport, 14(1), 98-110.

6. Gómez, M. A., Jiménez, S., Navarro, R., Lago-Penas, C., \& Sampaio, J. (2011). Effects of coaches' timeouts on basketball teams' offensive and defensive performances according to momentary differences in score and game period. European Journal of Sport Science, 11(5), 303-308. https://doi.org/10.1080/17461391.2010.512366

7. Herrera, G., Ramos, J.L., \& Mirella, J. (1996). Voleibol: manual de consulta operativa para el entrenador. Bilbao: Federación Vasca de Voleibol.

8. Mace, F. C., Lalli, J. S., Shea, M. C., \& Nevin, J. A. (1992). Behavioral momentum in college basketball. Journal of Applied Behavior Analysis, 25, 657-663. https://doi.org/10.1901/jaba.1992.25$\underline{657}$

9. Moreno, M. P., Santos J.A., \& Del Villar, F. (2005). La comunicación del entrenador de voleibol durante la dirección de equipo en la competición. Madrid: Real Federación Española de Voleibol.

10. Ortega, E. Martínez, JL., \& Martínez, G. (2007). Dirección de equipo en categorías de formación: intervención en la competición. In: Torres C. (Ed.). La formación del educador deportivo en baloncesto -Bloque Específico Nivel I- (Pp. 129-14). Sevilla: Wanceulen.

11. Permutt, S. (2011). The Efficacy of Momentum-Stopping Timeouts on Short-Term Performance in the National Basketball Association. Master's thesis in Economics. Haverford: Haverford College.

12. Roane, H. S., Kelley, M. E., Trosclair, N. M., \& Hauer, L. S. (2004). Behavioral momentum in sports: A partial replication with women's basketball. Journal of Applied Behavior Analysis, 37, 385-390. https://doi.org/10.1901/jaba.2004.37-385

13. Rodrigues J. (2000). O Desconto de Tempo e a Marcha do Marcador de Basquetebol. Trabajo fin de carrera. Oporto: Faculdade de Ciencias do Desporto e Educaçâo Física.

14. Sampaio, J., Lago-Pe-as, C., \& Gómez, M. A. (2013). Brief exploration of short and mid-term timeout effects on basketball scoring according to situational variables. European Journal of Sport Science, 13(1), 25-30. https://doi.org/10.1080/17461391.2011.582163

15. Sampaio, J., Lorenzo, A., \& Ribero, C. (2006). Momentos críticos en los partidos de baloncesto: metodología para identificación y análisis de los acontecimientos precedentes [Critical moments in basketball games: methodology for the identification and analysis of preceding events]. Cultura,Ciencia y Deporte, 5 (2), 83-88. https://doi.org/10.12800/ccd.v2i5.177

16. Tabachnick, B. G., \& Fidell, L. S. (2013). Using multivariate statistics (6th ed.). New Jersey: Pearson.

17. Valle, A., Antúnez, A., Sáez, F.J., García, A., \& Ca-adas, M. (2012). Estudio piloto sobre el uso, distribución y eficacia de los tiempos muertos de equipo en la liga asobal de balonmano. Ebalonmano. com: Revista de Ciencias del Deporte, 8(3), 191-199.

18. Wang, M. Y., Chen C. E., Lee S. C., \& Hsu, C. Y. (2010). A Study on the compilation of a Behavioral Scale for Timeout Decision of Taiwan's Table-tennis Players. International Journal of Table Tennis Sciences, 6, 21-27.

19. Zetou, E., Kourtesis, T., Giazitzi, K., \& Michalopoulou, M. (2008). Management and content analysis of timeout during volleyball games. Int J Perform Anal Sport, 8(1), 44-55.

20. Zhang, R. (1993). Preparación para la competición de equipos de alto nivel y el papel del entrenador durante el partido. International Volley Tech, 4(93), 2-5. 